\title{
Manejo de la biodiversidad: desarrollo sostenible y ecoturismo
}

\section{Patricia Cadenas Natalia lju}

\section{Introducción}

Desde que la Cumbre de la Tierra (Río de Janeiro, 1992) estableciera la guía para el desarrollo sostenible, a través de su Programa 21 , se constituyó un proyecto de largo alcance para mejorar las condiciones de vida a nivel mundial. Su puesta en práctica y su respectiva evaluación en el transcurso de diez años han sido materia de discusión en la Cumbre Mundial sobre el Desarrollo Sostenible, celebrada en Johannesburgo entre el 26 de agosto y el 4 de septiembre del 2002.

Los pilares para el desarrollo sostenible sobre los cuales se establecieron la Declaración de Río y la Agenda 21 (Cumbre Mundial sobre el Medio Ambiente y el Desarrollo o Cumbre de la Tierra_Río de Janeiro, 1992) constituyen objeto de preocupación actual en la comunidad internacional. La protección del medio ambiente, el desarrollo económico y el desarrollo social, así como el enfoque integrado y equilibrado de estos tres componentes debieran ser, desde Río 1992, las directrices que orienten las políticas gubernamentales de los países.

A nivel mundial, el Programa o Agenda 21 señala el viraje en las políticas gubernamentales, toda vez que en él se reconocía la necesidad de replantear las políticas de gobierno vigentes en los países, pues, de lo contrario, sólo se continuaría con las profundas divisiones económicas al interior de los países y entre ellos, con el aumento de la pobreza y el deterioro de los ecosistemas. Se proponía así el cambio hacia otra línea de conducta para proteger el planeta y crear un futuro más próspero, haciendo un llamado a la unión de las naciones y países del mundo.

El objetivo de la reunión de Johannesburgo, considerada como la evaluación y consolidación de los principios de la Cumbre de la Tierra, fue renovar el compromiso político con el desarrollo sostenible y plasmarlo en la Declaración de Johannesburgo, erigida como la expresión clara e inequívoca de los dirigentes y representantes mundiales que reafirmaron su determinación de trabajar por el desarrollo sostenible.

Durante el periodo de preparaciones para Johannesburgo, se celebraron cuatro' sesiones previas, conocidas como PreComs (Comités Preparatorios) con la finalidad de orientar el proceso mismo, crear conciencia política y

\footnotetext{
1 El décimo periodo de sesiones de la Comisión sobre el Desarrollo Sostenible de las Naciones Unidas, CSD10, se instituyó en Comité Preparatorio de la Cumbre y la institución organizadora central. Durante los años 2001 y 2002, la COS10 celebro cuatro sesiones preparatorias para la Cumbre Ilamadas CDS10 celobro Prem 2: 28 de enero - 8 de febrero de 2002, Nueva York; PreCom 3: 25 de marzo - 4 de abril de 2002, Nueva York; PreCom 4: 27 de mayo - 7 de junio de 2002, Bali, Indonesia.
} 
fomentar el apoyo a la cumbre entre los gobiernos y los grupos importantes -entre otros, la sociedad civil y las empresas- con la finalidad de que se presentasen iniciativas en colaboración y se aportasen soluciones a problemas especificos para lograr resultados concretos al desarrollo y conservación mundiales. De igual manera, se celebraron actividades complementarias a lo largo de la cumbre, con el propósito de compartir experiencias y abrir el diálogo entre los participantes de dichas reuniones oficiales, y otras, paralelas, convocadas y gestionadas por organizaciones o grupos independientes de las Naciones Unidas, como la Compañía para la Cumbre Mundial de Johannesburgo (JOWSCO).

Las áreas que generaron grandes expectativas entre los temas de mayor discusión para la Cumbre Mundial sobre el Desarrollo Sostenible (WSSD o CMDS) fueron esencialmente cinco: agua y saneamiento, energía, salud, productividad agrícola y el manejo de la biodiversidad y de los ecosistemas.

El cuidado de la diversidad biológica, materia de estudio en las líneas siguientes, es un aspecto concerniente a los asuntos de estado y que debe ser asumido con preocupación y compromiso por las políticas de gobierno de los paises. La diversidad biológica es un recurso vital muy importante y estratégico que supone los siguientes aspectos ${ }^{2}$ :

- Trasciende las divisiones geográficas o administrativas, razón por la cual se hace necesario el acuerdo entre los países para la aplicación de medidas regionales de protección y control para facilitar su conservación a largo plazo.

- Es de interés común a toda la humanidad, pero se ejerce el control soberano para su conservación y uso sostenible.

- Es un atributo de los ecosistemas biológicos que se manifiesta en todos los niveles jerárquicos, desde moléculas hasta biomas.

\footnotetext{
2 Aliredo Portilla, "Diversidad biológica: del concepto al potencial de la realidad" en Marcos Alegre et. al. El medio ambiente en el Perú. Año 2001, Desa, Lima,
2002: 272 .
}

- Es resultado de procesos ecológicos que se dan en un espacio definido y en un tiempo determinado.

- Es una característica de los seres vivos $y$, por ello, su naturaleza es dinámica y aleatoria.

La diversidad biológica incluye la cantidad y variedad de organismos que hay en el planeta, en una región, en un país o en un lugar, así como el contenido genético que les dio origen, producto de millones de años de evolución y las complejas relaciones y funciones del medio ambiente con los organismos. Puede decirse que el conocimiento que se tiene sobre ella, a nivel local como mundial, es todavía incipiente. Los estudios más completos corresponden a los grupos de mamíferos, aves, anfibios, peces y plantas con flores. Las especies descritas de vertebrados y plantas con semillas llegan a $90 \%$ y $80 \%$, en tanto que las del grupo de los invertebrados y artrópodos terrestres e invertebrados marinos han sido descritas en alrededor del $55 \%$ de las especies de cada grupo. Las algas que se conocen conforman el $17 \%$ de las especies de este grupo. El caso de los fungi, protozoos y bacterias es del $5 \%$ y el de los virus sólo representa el $1 \%$ del total de especies del grupo ${ }^{3}$.

Pero el interés que suscita el tema de la biodiversidad a nivel mundial no obedece a razones meramente de cantidad o incremento de la misma o de cuánto se haya podido conocer hasta el momento sobre la inmensa variedad de especies representadas en ella. La protección de la diversidad biológica es un tema prioritario y crítico, con implicancias sociales, económicas, ambientales, biológicas, éticas y estéticas. De los componentes de la diversidad biológica depende la existencia humana y aquí radica su importancia, he aquí la preocupación por su conservación. El mantenimiento de la biodiversidad garantiza el curso de la agricultura, de la ganadería, de las actividades forestales, de la pesca, de la medicina, de la industria y del turismo y aunque los recursos bio-

\footnotetext{
3 L. Hodriguez ed., Implementing the GTI: recommendations from DIVERSITAS Core Programme Element 3, including an assesment of present knowledge of key species groups. The International Union of Biological Sciences, Lima, 2000 cit. en Alfredo Portilla, "Diversidad biológica: del concepto al potencial de la realidad" en Marcos Alegre et. al., El medio ambiente en el Perú. Año 2001, Desa Lima, 2002: 275, 304
} 
lógicos sean renovables, su mal uso puede conducir a su pauperización. El potencial de estos recursos para nuevos productos agrícolas, medicinales e industriales, derivados de especies de plantas y animales, actualmente pocos conocidos e imposible de cuantificar con precisión, es enorme y la alteración o deterioro de la biodiversidad, generada por su mala utilización, merma la capacidad natural de los ecosistemas para generar beneficios, lo cual tiene un impacto económico que reduce la cantidad de bienes y servicios disponibles para la producción y el consumo. Por lo tanto, la conservación de la diversidad biológica (en sus tres niveles: intra específico o genético, específico y de ecosistemas) significa no sólo la preservación de unas cuantas especies de plantas y animales, sino la garantía del mantenimiento de las funciones (servicios) y el aprovisionamiento de materia prima (bienes) para la función productiva, contribuyendo así al desarrollo económico y al bienestar social.

El reconocimiento del Perú como país megadiverso no es simplemente una categoría atribuida como adorno. El Perú se encuentra entre los 12 países que albergan el $70 \%$ de la diversidad biológica a nivel mundial ${ }^{4}$. Los países reconocidos como "megadiversos" son ricos en ecosistemas, especies y recursos genéticos. Estos paises son: Brasil, Colombia, Ecuador, Perú, México, Zaire, Madagascar, Australia, China, India, Indonesia y Malasia. En términos de biodiversidad y medio ambiente, pueden ser considerados como potencias mundiales pues son los primeros, ocupando el Perú el cuarto lugar en biodiversidad y el noveno en aspectos endémicos.

El avance de las investigaciones y el conocimiento sobre biodiversidad en el Perú permiten saber el incremento del número de especies mamíferas en 99 desde los resultados obtenidos en 1990 ; las aves, en 7 especies; los reptiles, en 63; los anfibios, en 81 . De las 22000 especies de plantas vasculares estimadas en 1990 , se han reducido a un poco más de 17000

\footnotetext{
4 Para llegar a esta identificación de la biodiversidad en cada pais, se ha utilizado como indicadores el número total de especies y los niveles endémicos. tanto a niveles específicos como a niveles superiores de géneros y familias. Alfredo Portilla, "Diversidad biológica: del concepto al polencial de la realidad" en Marcos Alegre et. al., El medio ambiente en el Perú. Año 2001. Desa, Lima, 2002: 275.
}

en el transcurso de 10 años y las mariposas reportadas alcanzan las 2,607 especies 5 . El ajuste de las cifras se debe a la implementación de listas anotadas para el Perú, así como al uso de sistemas de clasificación en los que se han generado numerosas sinonimias, por lo cual el total de especies se ha reducido, de acuerdo a tratamientos taxonómicos recientes ${ }^{6}$.

Lo anterior demuestra y confirma que el Perú -según se ha dicho enésimas veceses un país con grandes potencialidades como para seguir permitiendo su continuidad y permanencia como un país en desarrollo. Lamentablemente, este status obedece a razones de políticas de gobierno mal llevadas, las mismas que están sujetas a parámetros internacionales que manejan la administración de los recursos naturales y culturales en base a sus intereses ${ }^{7}$. Por un lado, se proclama el mantenimiento de un desarrollo sostenido, se invierte y financian proyectos de investigación y de lucha contra la pobreza y desarrollo económico y social en las zonas más deprimidas del planeta, pero la otra cara de la moneda deja ver la irracionalidad con la que se comportan al favorecer y practicar actividades económicas no sostenibles por resultar más rentables, desde el punto de vista del individuo, que las actividades sostenibles, lo cual, a la larga, es un engaño pues socialmente todos salimos perdiendo. En el fondo, el Perú parece no haber evolucionado mucho desde que Raimondi acuñara su famosa pero deprimente frase "El Perú es un mendigo sentado en un banco de oro". Es hora de que los peruanos dejen de ser vistos como seres disminuidos o discapacitados que no logran acertar en el manejo y utilización de sus propios recursos. Es hora de dejar de lado aquellos comentarios de grupos conquistadores y viajeros decimonónicos europeos con

\footnotetext{
5 G. Lamas, "Estado actual del conocimiento de la sistematicidas de lepidópeteros, con especial referencia a la región neotropical" en Martin Piera et. al. ed. Hacia un proyecto CYTED para el inventario y la estimación de la diversidad biológica en lberoamérica. PrIBES, SAE, Zaragoza, 2000: 253-260 cit. en Alfredo Portilla. op. cit., Lima, 2002: 275, 304.

6 Comunidad Andina de Naciones (CAN). Taller: Conservación de ecosistemas transfronterizos y especies amenazadas. 26-28 de marzo de 2001, Lima, 2001

cit. en Alfredo Portilla, op. cit.. Lima, 2002: 275, 303 .
7 La posición de Estados Unidos es una clara expresión de esa realidad. No sólo no ha ratificado el Protocolo de Kyoto, principal acuerdo para protección del medio ambiente, sino que sus prácticas económicas producen el mayor porcentaje del deterioro ambiental y alteración de los ecosistemas a nivel mundial. Además, la Cumbre de Johannesburgo sobre el Desarrollo Sostenible no postuló acciones concretas que realmente favorezca a la disminución de la brecha - división entre los paises del norte desarrollados y ricos y los de sur, en desarrollo y pobres, siendo considerada por muchos criticos como un total fracaso.
} 
vencidos de que la única solución para la "civilización" de los pueblos conquistados es el sometimiento a las potencias colonizadoras que siempre vieron como despensas a sus colonias conquistadas. Las posibilidades están dadas y la realidad y la evolución del mundo demuestra que ni unos ni otros son independientes y que más vale una conciliación entre las partes que obligue a ceder quizá más de lo que se quiere o piense, pero que en definitiva asegura el beneficio equitativo y sostenido.

\section{La diversidad biológica}

Con la finalidad de comprender el término biodiversidad, se presentará primero una definición del mismo que permita identificar los elementos que la componen. El Convenio sobre la Diversidad Biológica ${ }^{8}$, ratificado en febrero del 2000 por 177 países señala que "la biodiversidad es la variabilidad de organismos vivos de cualquier fuente, incluidos, entre otras cosas, los ecosistemas terrestres y marinos y otros ecosistemas acuáticos y los complejos procesos ecológicos de los que forman parte; comprende la diversidad dentro de cada especie (genética), entre las especies y de los ecosistemas". El término implica de por sí diversidad, la cual está dada a nivel de los ecosistemas, especies y genes que hay sobre la Tierra y es resultado de procesos naturales y milenarios, junto a cambios climáticos y fisiográficos del paisaje, por medio de los cuales las especies evolucionan y se extinguen. Los factores que intervienen en dichos procesos no son antropogénicos (alteración del medio ambiente, introducción de especies y regímenes de selección), sino que constituye un conjunto dinámico variable en el tiempo y en el espacio ${ }^{9}$. Se incluye en ello a los diferentes lugares y formas de vida que existen sobre la Tierra, tanto los naturales como los creados por el ser humano (los agroecosistemas).

Biodiversidad es una categoría con un amplio espectro y por lo tanto tiene diversas

\footnotetext{
8 El texto completo está disponible en la página web del Convenio hillp://www biodiv.org.

9 Claudia Dary, Género y biodiversidad en comunidades indigenas de Centroamerica: un enfoque social sobre las formas de uso y conservación de los recursos naturales, FLACSO. Guatemala, 2002: 15 nota; Alfredo Portilla "Diversidad biológica: del concepto al polencial de la realidad" en Marcos Alegre et. al., El medio ambiente en el Perú. Año 2001, Desa, Lima, 2002: 271.
}

implicaciones. Abarca desde sus tres niveles o jerarquías (genes, las especies y los ecosistemas), sus componentes tangible (recursos biológicos en general) e intangible (conocimientos, las innovaciones y las prácticas humanas asociadas con la biodiversidad: técnicas agrícolas o los conocimientos científicos) hasta connotaciones valorativas de tipo económico, ecológico, ético, cultural, social, científico, educativo, recreativo y estético. Además, es un término que integra y ordena definiciones antiguas que recibian tratamientos e interpretaciones aisladas v. gr. los recursos flora, fauna, forestal, hidrobiológico, microorganismos, áreas protegidas, humedales, entre otros, reconociendo e incluyendo el papel de los procesos ecológicos en el mantenimiento de dichas formas de vida ${ }^{10}$.

\section{II.1 Niveles jerárquicos de la biodiversidad}

Los tres niveles de la biodiversidad no son excluyentes; por el contrario, éstos se compenetran a plenitud. Los genes están dentro de las especies y éstas constituyen una parte fundamental de los ecosistemas. La biodiversidad es una sociedad que funciona perfectamente y que ha sido formada durante millones de años. Su conservación incumbe a todos los habitantes de este planeta, y su pérdida implica graves consecuencias ecológicas, sociales y económicas.

\section{a. La diversidad intra específica o genética} se refiere a la variabilidad dentro de cada especie y se mide por la variación de los genes (unidades químicas de información hereditaria, transmitidas de una generación a otra) de una especie, subespecie, variedad o híbrido". Está relacionada con la capacidad de adaptabilidad de las especies a su entorno y desarrolla formas de resistencia a las enfermedades o condiciones ambientales adversas. Su importancia es muy grande

\footnotetext{
10 Altredo Portilla, Valoración económica de la diversidad biológica del Peru. Comité Peruano de UICN, Lima, 2000 (ms) cit. en Altredo Portilla, "Diversidad biológica: del concepto al potencial de la realidad" en Marcos Alegre et. al., EI medio ambiente en el Perú. Año 2001, Desa, Lima, 2002: 271, 304.

11 O.T. Solbrig ed. From Genes to Ecosystems: A research Agenda for Biodiversity, The International Union for Biological Sciencies (IUBS), Paris, 1991 cit. en Alfredo Portilla, "Diversidad biológica: del concepto al potencial de la realidad" en Marcos Alegre et. al., El medio ambiente en el Peñ. Año 2001. Desa, Lima, 2002: 271, 305.
} 
en los programas de domesticación, manejo genético y fuente de nuevas medicinas, permitiendo mejorar las cualidades de las especies domesticadas. La variabilidad de los genes se mide dentro de las poblaciones, utilizándose para ello datos moleculares, pero sólo se trabaja con algunos genes ya que el número de ellos en cada especie es muy elevado. Baste con apreciar, para hacerse una idea de ello, las diferentes variedades de cultivares de una sola especie. Las ferias de semillas son una de las formas de incentivar la preservación de la diversidad genética pues dan a conocer la biodiversidad latente existente entre los campesinos, ayudando a mantener asi el interés por su conservación. En los últimos años, en la sierra y selva peruanas, se han organizado este tipo de eventos ${ }^{12}$, sin embargo aún resultan escasos debido a la falta de iniciativas para su regularidad.

Los genes se encuentran en las células de los seres vivos y contienen los caracteres hereditarios que pasan de una generación a otra y definen características físicas (como el color de la piel o el sexo), controlan funciones reguladoras de la vida (como la elaboración de proteínas) o pueden albergar información relacionada con el comportamiento (mayor o menor agresividad). Las características genéticas hacen, asimismo, distintos a los diferentes miembros de una misma especie. Los genes no son copias exactas. Por ejemplo, en Latinoamérica existen numerosas variedades de maíz que contienen genes distintos. Esta diversidad propicia que algunas plantas sean resistentes a las plagas, mientras que otras son fácilmente infestadas.

La diversidad genética contempla la variabilidad dentro de cada especie, la misma que es muy vasta. Su conservación se ha convertido en un tema de debate muy actual en el mundo y en especial en los países del Sur, donde la erosión genética ocasionada por la utilización de pocas variedades, así como la fuga ilegal de material genético al exterior, constituye una amenaza grave a este recurso estratégico.

b. La diversidad especifica mide la variabilidad de las especies terrestres a escala local, regional o global, balanceando la presencia y la frecuencia de diferentes especies en una localidad determinada ${ }^{13}$. La diversidad de especies se refiere a la variabilidad de animales, plantas, hongos, virus $y$ otros microorganismos que habitan en un lugar determinado que puede ser toda la Tierra, un país, una región o una isla. Pero, las especies no están distribuidas uniformemente sobre el planeta, y hay paises que albergan cantidades más grandes de especies, pudiendo incluso, muchas de ellas, ser endémicas (aquéllas cuya distribución está restringida a un área específica). Por ejemplo, entre los bosques amazónicos y las lomas costeras, la variedad o riqueza de especies es diferente, lo mismo que entre la del fondo de una laguna continental y la del fondo marino.

Debido a que el número de especies en el mundo es sumamente grande, para facilitar los análisis se las clasifica en grandes grupos como mamíferos, aves, reptiles, anfibios, peces, insectos o plantas. En los bosques amazónicos existe una diversidad especifica o variedad taxonómica de aves, anfibios, mamíferos, mariposas, reptiles, peces, insectos, arañas, entre otras. La abundancia relativa de las especies determina si éstas son dominantes o si las abundancias de ellas son iguales, lo cual se puede expresar mediante algunos índices, tales como el de Shannon o el de Simpson.

\footnotetext{
12 En las ferias de semillas realizadas en la cuenca del Mayo Central (1993) se expusieron 509 cultivares, entre los que destacaron 12 variedades de yuca, 34 de platano, 18 de maiz, 42 de frijoles, 38 de ajies, 9 de papayas. Rengito, Crianza campesina de semillas en el Mayo Central San Martin. Centro de Desarrollo e Investigación de la Selva Alta, 1994 cit. en Aliredo Portilla, "Diversidad biologica: del conceplo al potencial de la realidad" en Marcos Alegre et. al., El medio ambiente en el Perú. Año 2001, Desa, Lima, 2002: 273, 304.
}

\footnotetext{
13 R.E. Ricklets el. al., "Conservation of Ecological Proceses" en Commission on Ecology Papers, 8, UICN, Gland, 1984 cit. en Alfredo Portilla, "Diversidad biológica: del concepto al potencial de la realidad" en Marcos Alegre et. al., El medio ambiente en el Peni. Año 2001. Desa. Lima, 2002: 273, 304.
} 
Una especie es un conjunto de organismos que comparten muchas características, entre ellas las genéticas, que se procrean o pueden reproducirse, en contraste a los híbridos como la mula que no pueden hacerlo. El oso de anteojos, el cedro y los seres humanos son ejemplos de especies.

c. La diversidad de ecosistemas toma en cuenta la interacción de la comunidad de organismos con su ambiente físico, vistos como una unidad ecológica ${ }^{14}$. Entre las causas de la diversidad de ecosistemas se tienen las diferentes condiciones climáticas y geográficas que ocurren en cada lugar. Por ejemplo, en los páramos andinos las plantas tienen hojas pequeñas para sobrevivir al frío, mientras que en la planicie amazónica, los árboles han desarrollado estrategias para aprovechar los escasos nutrientes del suelo tales como desplegar grandes raíces superficiales. Asimismo, en los bosques secos de la costa peruana viven especies adaptadas a un medio árido, el cual está determinado por la influencia de la corriente fría de Humboldt, fenómeno que provoca la disminución de las lluvias durante la mayor parte del año. La diversidad de ecosistemas comprende diferentes tipos de hábitats, de comunidades - poblaciones, de paisajes y de procesos ecológicos, no siempre definibles por la diferencia o gradualidad en que unos ecosistemas se engarzan con otros. Su conformación es de suma importancia para garantizar los procesos evolutivos de las especies y poblaciones que albergan. Dicha conformación está dada tanto por la comunidad biótica (productores: vegetales fotosintéticos y bacterias quimiosintéticas; y los consumidores: herbivoros y carnivoros), interdependiente de los aspectos abióticos del ambiente (agua, sales, sustancias orgánicas, oxígeno, anhídrido carbónico, acidez, presión, temperatura). La medición de la diversidad de los ecosistemas es muy difícil de medir en ciertos casos, tal como en el caso de los ecosistemas marinos ya que no existen límites geográficos entre ellos.
Un ecosistema está formado por una comunidad de organismos que interactúan entre sí y con el medio circundante. Los ecosistemas son complejas redes ubicadas en espacios geográficos determinados y que pueden ser naturales o creadas por los seres humanos, como los campos de cultivo o las ciudades. Son la biodiversidad en su nivel más alto y complejo: animales, plantas, hongos, virus y microorganismos en interacción con la lluvia, la temperatura, el suelo, la salinidad y otros factores. Algunos ecosistemas son los páramos, los manglares, los bosques amazónicos, el ecosistema de bosques inundables de selva baja y el de bosques enanos de la selva alta peruana.

Para la clasificación de los ecosistemas, el uso de tres métodos es frecuente en la actualidad. Uno es el sistema de clasificación de biomas biogeográficos, basado en mapas de vegetación, que permite clasificar los diversos niveles de ecosistemas en biomas, regiones y provincias biogeográficas. Fue producido por Udvardy (1975) $)^{15}$ y es el que más se utiliza en conservación como base para muchos procesos de planificación de áreas protegidas, como los seguidos en el Perú16. Otro método es el mapa de ecorregiones de los continentes ${ }^{17}$. Está basado en datos climáticos y de vegetación que clasifica asimismo los ecosistemas en tres niveles jerárquicos: dominios, divisiones y provincias. $Y$, por último, el sistema de clasificación de las zonas de vida de Holdridge (1967) ${ }^{18}$ que predice, según la existencia de ciertos da-tos climáticos (temperatura, precipitación y evapotranspiración), la vegetación que debe presentarse en cada zona. La Oficina Nacional de Recursos Naturales

15 M. D. Udvardy. "A classification of the Biogeographical Provinces of the World" en Ocasional Paper, 18, IUCN, Gland, 1975 cit. en Altredo Portilla. "Diversidad biológica: del concepto al potencial de la realidad" en Marcos Alegre et. al., El medio ambiente en el Peñ. Año 2001. Desa, Lima, 2002: 273, 305. 16 L. Rodriguez, ed., Diversidad biologica del Perú. Zonas protegidas para su conservacion, FANPE/GTZINRENA, Lima, 1996 cit. en Alfredo Portilla, op. cit., Lima, 2002: 273, 304-305. 17 R. G. Bailey, Ecorregions of the Continents, Departament of Agricultura Forest Service, Washington D.C., 1989 cit. en Alfredo Portilla, op. cit., Lima 2002: 273,303

18 L. R. Holdridge, Life Zone Eclogy, Tropical Science Center, San José, 1967 cit. en Alfredo Portilla, op. cit., Lima, 2002: 273, 304. 
$(1976)^{19}$ elaboró el Mapa Ecológico del Perú con el mapa de Holdridge, siendo combinado por el Centro de Datos para la Conservación (Universidad Nacional Agraria La Molina) para elaborar el Mapa de Provincias Biogeográficas. Siguiendo a Holdridge, en el Perú, se encuentran 84 zonas de vida de los 117 existentes a nivel mundial. Hay también 17 transiciones, además de contar con 28 tipos de clima. En el caso de los sistemas de montaña que se caracterizan por su heterogeneidad, fragilidad e inaccesibilidad, su clasificación podría realizarse bajo criterios agroecológicos, ${ }^{20}$.

\section{II.2 Tangibilidad e intangibilidad de la diversidad biológica}

La interacción de los elementos bióticos y abióticos, incluyendo la propia evolución humana contribuye al mantenimiento de la diversidad biológica. Se hace necesaria, por tal razón, la comprensión del ser humano como actor y promotor de la riqueza biológica, reflejada en la diversidad sociocultural. Ello conlleva decir que la diversidad cultural también debiera formar parte de la biodiversidad o diversidad biológica pues es innegable el conocimiento desarrollado por las comunidades indígenas en relación a la diversidad de plantas y animales de su entorno y acerca de las maneras de utilización de los recursos sin tener que llevarlos a su extinción, así como en el manejo de los bosques y los recursos hidrobiológicos y técnicas de transformación y conservación de alimentos y otros productos como medicinas, venenos entre otros ${ }^{21}$.

Desde esta comprensión de la interacción de los elementos bióticos y abióticos, que incluye la propia evolución de los elementos humanos para el mantenimiento de la biodiversidad, es posible estudiar la biodiversidad a partir de su tangibilidad (la naturaleza misma) y de su intangibilidad (lo que conocemos de ella).

\footnotetext{
19 Olicina Nacional de Recursos Naturales (ONERN), Mapa ecológico del Perú: guia explicativa, Lima, 1976 cil en Alfredo Portilla, op. cit., L.ima, 2002: 273. 304 .

20 Altredo Portilla, op. cit., Lima, 2002: 273

21 Claudia Dary, op cit. Guatemala, 2002: 30-31 y Antonio Brack -Comunidades nativas como centros de conocimientos tradicionales" en Amazonia peruana, comunidades indigenas, conocimientos y tierras tituladas. Atlas y base de datos, GEF/PNUD/UNOPS, Lima, 1997 cit. en Altredo Portilla, op. cit. Lima, 2002: 275,303
}

El carácter tangible de la biodiversidad está conformado por la variedad de genes, de especies y de ecosistemas que podemos identificar, manejar y usar. Lo conforman el material genético, las poblaciones naturales y los recursos de los ecosistemas que pueden ser evaluados físicamente. De esta manera, los árboles, peces comerciales y plantas medicinales forman parte del carácter tangible de la biodiversidad.

El caracter intangible de la biodiversidad viene a ser toda la variedad de conocimientos, innovaciones y prácticas, individuales 0 colectivas relacionadas con la diversidad biológica. Aquí se incluyen los saberes de los pueblos indígenas y de las comunidades campesinas, así como las tecnologías modernas y las innovaciones científicas para usar los recursos.

El conocimiento tradicional se refiere a los saberes, a las innovaciones y a las prácticas de comunidades indígenas y locales del mundo, producto de toda la experiencia ganada a través de los siglos en el ambiente local. Es una clase de conocimiento que se transmite en forma "viva" de generación en generación y de manera oral. Su valor o utilidad no sólo es significativo para los que dependen de él en sus vidas diarias, sino también para la industria y la agricultura modernas.

El grado de contribución del conocimiento tradicional de los pueblos del mundo al desarrollo inteligente del hombre puede ser en extremo grande. Las explicaciones a esta afirmación pueden estar basadas en el hecho de que las comunidades indígenas y locales están situadas en las áreas donde se encuentran la mayoría de los recursos genéticos de las plantas, las cuales han sido domesticadas, cultivadas y transformadas por dichos grupos locales hábilmente a través del desarrollo y perfeccionamiento de técnicas propias que proporcionan información valiosa a la comunidad global y un modelo útil para las políticas de sostén y aprovechamiento de la biodiversidad.

El reconocimiento del aporte del conocimiento del saber indígena o tradicional al saber o conocimiento científico occidental está reconocido en el Convenio de la Diversidad Biológica. Esta contribución está señalada en 
términos de conservación y uso sostenible de la diversidad biológica esencialmente. El artículo 8(j) del Convenio impone a las legislaciones nacionales, el respeto, preservación y retribución de esos aportes que las comunidades indígenas y locales que incorporan las formas de vida tradicionales relevantes para la conservación y el uso sostenible de la diversidad biológica y promueve su aplicación más amplia.

\section{Manejo de la biodiversidad: sostenibilidad y turismo}

Frente al deterioro alarmante de los ecosistemas de la Tierra, el desarrollo sostenible se ha definido como el desarrollo que resuelve las necesidades del presente sin mermar o perjudicar la capacidad de las generaciones futuras de resolver sus propias necesidades, lo cual implica mejorar las condiciones de la calidad de vida a nivel mundial, mediante el mejor uso de los recursos naturales y sin sobrepasar la capacidad de carga de la Tierra.

El pronunciamiento de los pueblos indígenas, paralelamente a las reuniones de Johannesburgo, se evidencia en el Plan de Acción de los Pueblos Indígenas sobre el desarrollo sostenible. Éste refleja el sentimiento y el pensamiento de los pueblos indígenas como guardianes de la madre tierra que, a lo largo de milenios, han conservado y mejorado sus sociedades de manera sostenible. El documento oficial de la Cumbre Mundial sobre el Desarrollo Sostenible también se pronuncia a favor del papel de estos pueblos en pro de la sostenibilidad del mundo, aunque es la convención sobre la que, a continuación de Río 1992, se impone el reconocimiento, preservación y promoción del conocimiento tradicional de los pueblos indígenas.

Como resultado del trabajo desplegado en esta convención, los gobiernos comenzaron a facilitar la participación de comunidades indígenas y locales en las políticas para la conservación y el uso sostenible de recursos, del acceso a los recursos genéticos y de la distribución de los beneficios, así como la gerencia de áreas protegidas. Se avanza en el proceso de poner en práctica planes, estrategias y programas nacionales de acción sobre la biodiversidad, adoptando leyes específicas, políticas y reglamentos administrativos para proteger el conocimiento tradicional, previo involucramiento, información y consentimiento de dichas comunidades.

El respeto por el conocimiento tradicional se hace cada vez mayor, lo cual hace replantear los procedimientos de la ciencia moderna con fines de adaptación, mediante la evaluación del impacto de los proyectos de desarrollo sobre la diversidad biológica; obliga a vigilar los ecosistemas, recursos genéticos y a promover la conservación in situ.

Importa también la participación activa de las comunidades indígenas y locales y la aplicación activa de sus conocimientos y tecnologías en la conservación y el uso sostenible de bosques, biodiversidad agrícola, aguas de tierra adentro, ecosistemas costeros y marinos y en el desarrollo del ecoturismo.

\section{III.1 Turismo sostenible y el ecoturismo}

Cuando Thomas Cook (1841) organizó la primera excursión en tren de Leicester a Longhborough (570 pasajeros), se dio impulso a uno de los más grandes fenómenos sociales del siglo $X X$, el llamado turismo de masas. No obstante su evolución deje ver la exclusividad con que reducidos grupos de personas hacían de dicha actividad su patrimonio de clase, a finales del siglo XIX, el turismo había dejado de ser un fenómeno exclusivo de una minoría aristocrática, transformándose en una actividad de ocio de la que también podían participar otros sectores de la sociedad.

El turismo se ha desarrollado con muy grandes implicancias económicas y sociales en el siglo $X X$, a cuyo empuje han contribuido numerosos factores socioeconómicos y tecnológicos. En los años 70, llega a ser un fenómeno de masas en los países más desarrollados, que requería cada vez más de gran infraestructura y complejos servicios. Este crecimiento se ha sustentado en el llamado modelo turístico convencional de "avión, hotel y playa" que a mediados de los ochenta empezó a representar sintomas de agotamiento y de crisis en ciertas zonas del Mediterráneo europeo. 
La pérdida de la calidad y el valor de la vacación ofrecida por el modelo turístico convencional ha generado una nueva corriente en los países desarrollados que son los principales generadores de la demanda, el llamado turismo alternativo que viene a ser el resultado de cambios en los valores y hábitos de vida ocurridos en las poblaciones de los países desarrollados, que procuran mejorar su calidad de vida, a través de nuevas formas de utilización del tiempo libre y la conservación de un ambiente limpio.

La Organización Mundial del Turismo (OMT) señala el crecimiento acelerado del segmento turismo alternativo que incluye, entre otras especialidades de la actividad turística, al ecoturismo, caracterizado como el turismo centrado en la naturaleza. Sin embargo, los conceptos de turismo de naturaleza y ecoturismo suelen confundirse muy a menudo, aunque ambos impliquen actividades turísticas en zonas naturales, existen diferencias que hacen que cada uno de ellos tengan sus propias características. Mientras que el primero es el conjunto de actividades turísticas que se ejecutan en áreas naturales, sea que formen o no parte del patrimonio de áreas naturales del estado, y no incluye la participación de las comunidades locales. El ecoturismo ${ }^{22}$ dentro de su definición debe considerar no sólo el hecho de realizar actividades turísticas, la noción de movimiento o viaje a una zona natural, sino también se añaden tres elementos importantes que van a marcar la diferencia. El primero de ellos es estar intimamente ligado a la naturaleza, lo que involucra viajar por países en vías de desarrollo, a marcos relativamente vírgenes, con fines de estudio, disfrute o para intervenir en programas de ayuda voluntaria relacionada con la flora y fauna del lugar, asi como con la gente (cuidadores) que vive en las zonas próximas, sus necesidades, su cultura y su relación con la tierra, además el ecoturismo puede lograr que la naturaleza rejuvenezca rehabilitando zonas degradadas por la actividad humana y así aportar de manera concreta al medio ambiente y a la

\footnotetext{
22 En la Cumbre Mundial del Ecoturismo (Québec, Canadá, del 19 al 22 de mayo 2002) se estableció que el ecoturismo debe ser considerado como todo tipo de turismo basado en la observación y apreciación de la naturaleza, asi como de las culturas tradicionales prevalecientes en las zonas naturales. Su significado y práctica implican experiencias de interpretación y aprendizaje (crea conciencia y provoca cambios de actitud) y es una actividad, por lo general, ca. racterizada por su alta especializacion y orientada a grupos reducidos, organizada por empresas locales.
}

vez proporcionar un beneficio directo a la comunidad local. El segundo, es su orientación hacia la conservación, el cual ha surgido como consecuencia de la creciente preocupación global por la desaparición de culturas y ecosistemas y como expresión del rechazo al desarrollo inadecuado del turismo que puede deteriorar una zona protegida y producir efectos imprevistos desde el punto de vista económico, social y medioambiental en los territorios circundantes. El tercer elemento es su función educativa, el cual se refiere no sólo a los propios turistas sino también a los operadores de la industria del turismo y a las comunidades locales. El ecoturismo atrae a personas que desean interactuar con el medio ambiente y ampliar sus conocimientos sobre él, a su vez, proporciona a los miembros de las comunidades locales la oportunidad de aprender más acerca de los puntos atractivos que los turistas desean visitar y lograr así que la comunidad receptora aprecie sus propias tradiciones culturales como resultado del interés que los turistas muestran por ellas ${ }^{23}$.

El ecoturismo se basa en criterios de desarrollo sostenible ${ }^{24}$, el cual se define como "el desarrollo que satisface las necesidades del presente sin comprometer la capacidad de las generaciones futuras de satisfacer sus propias necesidades"25. Cuestionar dicho concepto al parecer resultaría absurdo, sin embargo, a lo largo de la historia se han presentado diversas situaciones que nos hacen reflexionar acerca de la falta de criterios adecuados que fueron utilizados en el uso de los recursos naturales. Para empezar este recorrido histórico se mencionará al filósofo escocés John Locke (1632 - 1704) quien afirmó que todo lo que hay en la naturaleza es desperdicio hasta que las personas lo transforman en cosas de valor utilizables ${ }^{26}$. También se pueden apreciar casos similares en

\footnotetext{
23 John Neil et. al.. Ecoturismo. Impacto, tendencias y posibilidades, Sintesis, Madrid. 1999: 30, 31, 33.

24 La cumbre de Québec señala la importancia del ecoturismo en el desarrollo de la sostenibilidad porque minimiza el impacto negativo sobre el medio natural y sociocultural y apoya a la protección de zonas naturales pues genera beneficios económicos a las comunidades receptoras y a los organismos y autoridades que gestionan estas zonas con objetivos de conservación, constituye una alternativa de empleo y de obtención de rentas para las comunidades locales y contribuye a la sensibilización de las poblaciones locales y de los turistas respecto de la conservación de los bienes naturales y culturales.

25 Oxford University, Comisión Mundial para el Medio Ambiente y Desarrollo. Australiana, Melbourne, 1987 cit. en John Neil at. al., Ecoturismo. Impacto, tendencias y posibilidades, Sintesis, Madrid, 1999: 29.

26 John Locke, Un ensayo referente a la comprensión humana, 1976(1690) cit. en John Neil at. al., Ecolurismo. Impacto, tendencias y posibilidades, Sintesis, Madrid, 1999: 36
} 
tiempos más recientes. En diciembre de 1987 se concedió el premio Nobel de Economía al estadounidense Robert Solow por su teoría sobre el conocimiento económico, donde afirma que "el mundo puede salir adelante sin recursos naturales, así que el agotamiento de dichos recursos es simplemente un suceso, no una catástrofe", lo cual muestra su nulo interés por la conservación de la naturaleza al considerarla prescindible. Aún más reciente, es el caso del ex - presidente de los Estados Unidos, George Bush, en 1992, quien antes de partir hacia la Cumbre de la Tierra organizada por las Naciones Unidas en Brasil dejó clara su posición y la de su país de negarse a firmar tratados o documentos que se deriven en controles medioambientales que pudieran frenar el crecimiento económico de los Estados Unidos ${ }^{27}$. Entonces, dados éstos antecedentes, el desarrollo sostenible parecería ser un concepto utópico y es que, si éste era el pensamiento del presidente de los Estados Unidos de Norteamérica, ¿qué se puede esperar entonces de los presidentes de países en desarrollo y de sus habitantes, los cuales sufren de mayores carencias educativas y económicas?.

El desarrollo sostenible es más difícil de llevar a cabo en zonas de extrema pobreza. Es por ello que proyectos en los que participan comunidades locales ${ }^{28}$ deben ser fomentados, de manera que éstas puedan tener un mayor beneficio económico y así mejorar su nivel de vida. El proyecto de ecoturismo Posada

\footnotetext{
27 John Neil et. al., Ecoturismo. Impacto, tendencias y posibilidades, Sintesis, Madrid, 1999: 36, 37

28 La Declaración de Québec define como imprescindible la paricipación de las comunidades receptoras en todo el proceso de planificación e implementación de cualquier proyecto de ecoturismo en aquellas zonas donde se detecta la presencia de grupos locales históricamente arraigados. Existe, además, la necesidad de identificar la propiedad de la tierra, a través de mecanismos que establezcan y registren los derechos sobre la misma, asi como de reconocer y mejorar la capacidad de las comunidades de ejercer control sobre la gestión del directa como indirectamente. mediante programas de capacitación o de formación. Por otro lado, se priorizan a las Áreas Naturales Protegidas (ANP) en el desarrollo del ecoturismo pues cumplen y están creadas par los objetivos de conservación y porque el desenvolvimiento del turismo en ellas se constituye en fuente muy imporante de ingresos para las mismas y para la misma razón por la cual fueron creadas. Adem organismos de asistencia al desarrollo y organismos de financiación internacional, sector privado (con especial enfasis en las pequeñas empresas), operadores turisticos, QNGs, asociaciones basadas en la comunidad, instituciones académicas y de investigación, comunidades locales y organizaciones municipales. El carácter integral con que debe llevarse a cabo exige el desarrollo de politicas y la planificacion del ecoturismo, debido justamente a las distintas participaciones que genera. Ello significa incorporar procesos consultivos de manera global y transparente, haciendo esfuerzos por incluir a los grupos más desfavorecidos y a los que tradicionalmente se les ignora (grupos indigenas, mujeres, tercera edad y jóvenes), creando, a su vez, objetivos y beneficios para la comunidad.
}

Amazonas ${ }^{29}$, en Perú, cumple a cabalidad con el concepto anteriormente mencionado de ecoturismo y ha sido posible gracias a una alianza estratégica entre una empresa privada y una comunidad local y ha dado como resultado la apertura en 1998 del albergue Posada Amazonas, ubicado en las proximidades de la Reserva Nacional Tambopata, en el sur este de la selva amazónica del Perú. Desde que el albergue inició sus operaciones los pobladores que trabajan allí han mejorado sustancialmente su nivel de vida, tanto en el aspecto laboral y económico (de 20 puestos de trabajo brindados en el albergue 17 son ocupados por los comuneros), como en el educativo, ya que las personas interesadas tuvieron la posibilidad de recibir un curso de introducción al ecoturismo además de otros cursos de capacitación como la enseñanza del idioma inglés. Es importante también resaltar que con el 20 por ciento de las utilidades que reciben han implementado la primera escuela secundaria rural piloto artesanal en el río Tambopata, lo que indica que son concientes de la importancia de la educación y su repercusión en el ámbito económico y social. Se ha logrado también revalorar la labor de los artesanos, gracias a la comercialización de sus productos en el albergue y a los constantes talleres de capacitación.

Uno de los atractivos principales del albergue está relacionado con la observación de los animales, lo que genera un interés más fuerte por conservar la flora y fauna existente en el lugar. Esta actitud se ve reflejada en el apoyo económico destinado a proyectos de conservación local y desarrollo sostenible que son utilizados para la adquisición de equipos especializados con la finalidad de satisfacer las necesidades de observación y disfrute de la naturaleza por parte de los turistas y que a su vez que no generen ruidos y perturben a la fauna existente. Otra de las acciones realizadas por la comunidad y que contribuyen de manera sustancial a la conservación del medio ambiente es el tratamiento dado a los desperdicios, los que son almacenados y reciclados o usados como abono natural y las aguas servidas son deposi-

\footnotetext{
29 Miguel Pesha y Francisco Cala, El ecoturismo como altemativa para el desarrollo sostenible de las comunidades nativas en: Econegocios, biocomercio y servicios ambientales, Lima, 2002.
} 
tadas en pozos de sedimentación y oxidación. Además en el futuro se planea instalar bio-gas y calentadores solares de agua e iluminación.

Otro proyecto peruano a tomar en consideración es aquél que vienen realizando FANPE (Fortalecimiento del Sistema Nacional de Áreas Naturales Protegidas por el Estado), INRENA (Instituto Nacional de Recursos Naturales) y GTZ (Cooperación Técnica Alemana $)^{30}$. Uno de los objetivos del proyecto es lograr la protección del espacio en el que se desarrollan minorías étnicas en áreas protegidas para lograr la conservación de los sistemas ecológicos, para ello se brinda apoyo a dos comunidades, una es la Matsiguenka y la otra es Tayakome y Yomibato, las que se desarrollan a orillas del río Manu en la reserva de la biósfera y el Parque Nacional Manu. El proyecto FANPE / GTZ asesora a los Matsiguenka en la empresa multicomunal Matsiguenka denominado "Casa Matsiguenka" que es un albergue de estilo tradicional visitado por turistas desde 1999, con esto no sólo se pretende el conocimiento del bosque tropical sino también de las etnias que habitan en este ecosistema.

Patricia Cadenas Erazo

Instituto de Investigación

Escuela Profesional de Turismo y Hotelería

Universidad de San Martin de Porres mcadenas@turismo.usmp.edu.pe

Natalia lju Ireijo

Instituto de Investigación

Escuela Profesional de Turismo y Hotelería Universidad de San Martin de Porres niju@turismo.usmp.edu.pe 